\title{
Predição de frações digestíveis e valor energético de subprodutos agrícolas e agroindustriais para bovinos
}

\author{
José Augusto Gomes Azevêdo ${ }^{1}$, Sebastião de Campos Valadares Filho ${ }^{2,8}$, Edenio Detmann², \\ Douglas dos Santos Pina ${ }^{3}$, Luiz Gustavo Ribeiro Pereira ${ }^{4}$, Karla Alves Magalhães de \\ Oliveira $^{5}$, Henrique Jorge Fernandes ${ }^{6}$, Natália Krish de Paiva Souza ${ }^{7}$
}

\author{
${ }^{1}$ DCAA/Universidade Estadual de Santa Cruz. Membro do INCT em Ciência Animal. \\ 2 DZO/Universidade Federal de Viçosa. Pesquisador do CNPq. \\ ${ }^{3}$ DZO/Universidade Federal de Mato Grosso. \\ ${ }^{4}$ Embrapa Gado de Leite. \\ 5 DZO/Universidade Estadual Paulista - Jaboticabal. \\ ${ }^{6}$ Universidade Estadual de Mato Grosso do Sul. \\ ${ }^{7}$ DZO/Universidade Federal de Viçosa. \\ ${ }^{8}$ Coordenador do INCT em Ciência Animal.
}

RESUMO - Objetivou-se avaliar equações adotadas pelo NRC e Detmann para estimar o conteúdo energético de subprodutos agrícolas e agroindustriais. Foram avaliados subprodutos de abacaxi, cacau, dendê, feijão, girassol, goiaba, mandioca casca, mandioca haste, mandioca rama, mamão, manga, maracujá, nabo e farelo de glúten de milho. Todos os animais receberam silagem de milho e mistura ureia/sulfato de amônio (9:1) para que as rações com os dois níveis de cada subproduto se mantivessem isonitrogenadas. Entre os modelos de predição da proteína bruta digestível (PBad), o modelo Detmann 2 apresentou diferença pelo teste de hipótese para nulidade conjunta (THNC), enquanto as estimativas pelos modelos NRC e Detmann 1 foram similares às obtidas pelas observações in vivo. Para extrato etéreo digestível (EEad), carboidratos não-fibrosos digestíveis (CNFad) e fibra em detergente neutro digestível (FDNd), as estimativas obtidas pelo modelo proposto pelo NRC diferiram, pelo teste de significância da hipótese de nulidade conjuntas, das observações in vivo e o melhor ajustamento foi obtido pelo modelo sugerido por Detmann, tendo como consequência, o valor. No entanto, entre todas as frações digestíveis, a FDNd foi a que apresentou maior dispersão dos pontos em relação à linha de equalidade. Os modelos NRC e Detmann podem ser considerados eficientes em predizer nutrientes digestíveis totais (NDT) e energia digestivel (ED), pois as estimativas não diferem dos valores observados, contudo apresentam também grande dispersão dos pontos em relação à linha de equalidade. Recomenda-se usar os modelos propostos por Detmann para predizer as frações digestíveis da PB, EE e dos CNF em subprodutos agrícolas e agroindustriais.

Palavras-chave: equações, nutrientes digestíveis totais, resíduos

\section{Prediction of digestible fractions and energy value of agriculture and agroindustrial byproducts for bovines}

\begin{abstract}
The objective of this work was to evaluate the equations adopted by the NRC and Detmann to estimate the energy content of agricultural and agroindustrial byproducts. It was evaluated byproducts of pineapple, cocoa, palm oil, beans, sunflower, guava, cassava bark, cassava stem, raw cassava, papaya, mango, passion fruit, turnip and corn gluten meal. All animals received corn silage and the mixture urea/ammonium sulfate (9:1) so rations with the two levels of each byproduct remained isonitrogenous. Among the models for digestible crude protein prediction (CPad), Detmann 2 model presented difference by the hypotheses test for joint null while estimates by the NRC and Detmann 1 models were similar to those obtained by in vivo observations. For digestible ether extract (EEad), digestible non-fibrous carbohydrates (NFCad) and digestible neutral detergent fiber (NDFd), the estimates obtained by the model proposed by the NRC differed, by the test of significance of hypotheses of joint null, to in vitro observations and the best adjustment was obtained by the model suggested by Detmann, having as a consequence, the value. However, among all the digestible fractions, NDFd presented the greatest dispersion of points regarded to equality line. NRC and Detmann models can be considered as efficient in predicting total digestible nutrients (TDN) and digestible energy (DE) because the estimates do not differ from the observed values, however they also present great dispersion of the points regarded to equality line. It is recommended to use the models proposed by Detmann for predicting digestible fractions of crude protein, ether extract and non fibrous carbohydrates on agriculture and agroindustrial byproducts.
\end{abstract}

Key Words: equations, total digestible nutrients, residuals 


\section{Introdução}

O valor nutritivo dos alimentos é resultado de um conjunto de transformações, mecânicas e químicas que os alimentos sofrem durante sua permanência no trato gastrintestinal. Após o conhecimento da composição química, a obtenção de estimativas dos coeficientes de digestibilidade é reconhecidamente essencial para se quantificar o valor nutritivo dos alimentos (Valadares Filho et al., 2000).

Nos estudos de digestibilidade em bovinos, os resultados obtidos in vivo sempre foram mais realísticos, contudo, são limitados pela necessidade de se ter número representativo de animais, além de exigir grande quantidade de alimentos que permita ser utilizada durante os períodos de adaptação e experimental.

Conrad et al. (1984), posteriormente, Weiss et al. (1992) e mais recentemente sob condições tropicais Detmann et al. (2004, 2006a,b,c, 2007) propuseram a utilização da composição química dos alimentos como método alternativo de predição da digestibilidade em ruminantes.

Nessa perspectiva, o NRC (2001) e Detmann et al. (2008b) propuseram um método para estimação do teor de NDT dos alimentos, o qual se constitui de um sistema de equações somativas, de modo que, a cada grupo de compostos químicos, se destinam uma equação para obtenção de estimativas das frações verdadeiramente digestíveis, com posteriores correções no tocante às perdas metabólicas e ao nível de consumo.

Embora o NRC (2001) seja um sistema amplamente difundido e, teoricamente, satisfatório para o uso em condições temperadas, esse conjunto de equações não tem apresentado eficiência de predição satisfatória quando aplicado a alimentos obtidos em condições tropicais, tornando as estimativas substancialmente desviadas dos valores observados in vivo (Rocha Júnior et al., 2003; Costa et al., 2005; Oliveira et al. 2007; Silva et al., 2007).

Como a variação na composição química e no conteúdo de energia de subprodutos agrícolas e agroindustriais é maior do que a dos concentrados e volumosos e considerando que as equações de predição do valor energético foram desenvolvidas, principalmente, com dados de volumosos e concentrados (NRC, 2001), objetivou-se avaliar a acurácia das equações adotadas pelo NRC (2001) e Detmann et al (2008b), para estimar o conteúdo energético de subprodutos agrícolas e agroindustriais.

\section{Material e Métodos}

O trabalho foi conduzido no Departamento de Zootecnia, do Centro de Ciências Agrárias, da Universidade Federal de Viçosa, em Viçosa, Minas Gerais e a fase de campo foi realizada no período de junho a setembro de 2006.

Foram avaliados os subprodutos de abacaxi (Ananas comosus), cacau (Theobroma cação), dendê (Elaeis guineensis), feijão (Phaseolus vulgaris), girassol (Helianthus annuus), goiaba (Psidium guajava), mandioca (Manihot esculenta) casca, haste e rama, mamão (Carica papaya), manga (Mangifera indica), maracujá (Passiflora ligularis), nabo (Raphanus sativus) e farelo de glúten de milho (Zea mays).

Foram utilizadas 20 novilhas, nelores e aneloradas, em fase de crescimento, com peso vivo médio inicial de $273 \pm 37 \mathrm{~kg}$. Antes de se iniciar o experimento, todos os animais foram pesados, tratados contra ecto e endoparasitas. Após a primeira pesagem, efetuou-se a distribuição dos animais de forma casualizada em cada tratamento.

Os animais foram mantidos em regime de confinamento, alojados em baias individuais cobertas, com piso de concreto revestido de borracha, de $3 \times 3 \mathrm{~m}$ de área, dotadas de comedouros de alvenaria e bebedouros individuais.

Considerou-se para efeito de controle local do experimento que os subprodutos estivessem combinados em dois níveis (alto e baixo), com quatro repetições para cada nível, a partir de um delineamento em reversão simples. Os mesmos quatro animais foram utilizados nos dois níveis do subproduto no mesmo período, sendo que no segundo período, os animais alimentados com dietas contendo menor nível do subproduto receberam o nível maior, enquanto, aqueles que receberam nível maior de subproduto na ração no período anterior, receberam no segundo período nível menor. Cada tratamento foi representado por uma fonte e nível de subproduto na dieta.

Em cada período avaliaram-se cinco subprodutos, com duração de 15 dias, sendo 12 dias de adaptação e três dias de coleta total de fezes e urina, totalizando 90 dias de período experimental, seis períodos experimentais com avaliação total de 14 subprodutos, considerando que no quinto período avaliou-se também a silagem de milho sem inclusão de subproduto, mas com 2,22\% de uréia na MS total.

Todos os animais receberam silagem de milho na mesma proporção e foi utilizada a mistura uréia/sulfato de amônio (9:1) para que as rações contendo os dois níveis de cada subproduto se mantivessem isonitrogenadas. As dietas foram fornecidas duas vezes ao dia, às 6 h00 (60\% da oferta) 
e $15 \mathrm{~h} 30$ ( $40 \%$ da oferta), de forma a permitir consumo ad libitum (sobras de $5-10 \%$ da quantidade fornecida). A quantidade de alimento fornecida foi ajustada diariamente, a partir do consumo observado no dia anterior, e as sobras foram pesadas diariamente.

Foi realizada a coleta total de fezes dos animais em cada período experimental, por um período de 72 horas, registrando-se a quantidade total excretada por animal. Durante a pesagem das fezes e após homogeneização, foram retiradas alíquotas de, aproximadamente, 5\%, para posterior confecção das amostras compostas de cada animal. Durante o período de coleta de fezes, foram registradas as quantidades de alimento consumido diariamente, coletando-se amostras dos alimentos oferecidos por tratamento e das sobras por animal.

As amostras de alimentos, sobras e fezes foram devidamente armazenadas $\left(-20^{\circ} \mathrm{C}\right)$ e, posteriormente secas em estufa de ventilação forçada, a $60^{\circ} \mathrm{C}$ por 72 horas, moídas com peneira de malha de 1 mm e submetidas às análises laboratoriais.

Os coeficientes de digestibilidade aparente da proteína bruta (PB), do extrato etéreo (EE), da fibra em detergente neutro (FDN) e dos carboidratos não-fibrosos (CNF) de cada subproduto utilizado neste estudo foram obtidos a partir dos coeficientes médios de digestibilidade das dietas específicas de cada tratamento, por sistema de equações lineares (Silva \& Leão, 1979).

Todos os subprodutos coletados foram secos a $60^{\circ} \mathrm{C}$ durante 72 horas e moídos em moinho de facas com peneira de porosidade de $1 \mathrm{~mm}$ de diâmetro, para posteriores análises do conteúdo de matéria seca (MS), PB, matéria orgânica (MO), EE e fibra em detergente ácido (FDA), conforme os métodos do AOAC (1990).

Nas análises de FDN, as amostras foram tratadas com alfa-amilase termo-estável, sem o uso de sulfito de sódio e corrigido para cinzas residuais (Mertens, 1992). A correção da FDN e FDA para os compostos nitrogenados e a estimação dos conteúdos de compostos nitrogenados insolúveis em detergente neutro (NIDN) e ácido (NIDA) foram feitos conforme Licitra et al. (1996). Os conteúdos de lignina foram obtidos por meio da solubilização da celulose pelo ácido sulfúrico (Van Soest \& Robertson, 1985).

Os conteúdos de CNF da MS dos subprodutos, expressos em \% na MS, foram calculados de acordo com Hall (2000) como 100- (\%FDN + \%PB + \%EE + \%MM) e os nutrientes digestíveis totais (NDT) foram calculados como: NDT = \%PBdigestível + \%FDNdigestível + \%CNFdigestível + 2,25*\%EEdigestível.

A partir da composição química dos subprodutos (Tabela 1) foram estimados os valores das frações digestíveis, NDT e energia digestível (ED), conforme as equações propostas por Weiss et al. (1992) e adotadas pelo NRC (2001), além das sugeridas para animais em crescimento e terminação em consumo voluntário, por Detmann et al. (2006a, 2006b, 2006c, 2007, 2008a), que estimam os teores aparentes digestíveis das frações de proteína bruta (PBad), extrato etéreo (EEad) e carboidratos não-fibrosos (CNFad), além dos teores digestíveis da fração da fibra em detergente neutro livre de proteínas (FDNd):

— PBad (para alimentos concentrados $)=\mathrm{PB} \times[1-(0,4$ $\times$ PIDA/PB)]-2,7 (NRC, 2001);

- PBad (para alimentos volumosos) $=\mathrm{PB} \times \operatorname{Exp}[-1,2 \times$ (PIDA/PB)]-2,7 (NRC, 2001)

— $\mathrm{PBad}=0,7845 \times \mathrm{PB}-1,61$ (Detmann et al., 2006a);

$-\mathrm{PBad}=0,98 \times($ PB-PIDN $)+0.835 \times($ PIDN - PIDN $)-$

1,61 (Detmann et al., 2008a);

$$
- \text { PIIDN }=\left(\left(1,1557+0,0255 \times\left(\text { PIDA }^{2,3388}\right)\right)^{2}\right.
$$

(Detmann et al., 2010);

Tabela 1 - Composição química dos 14 subprodutos agrícolas e agroindustriais

\begin{tabular}{|c|c|c|c|c|c|c|c|c|c|c|}
\hline Item & $\begin{array}{l}\text { Matéria } \\
\text { seca (\%) }\end{array}$ & $\begin{array}{l}\text { Matéria } \\
\text { orgânica } \\
\text { (\% MS) }\end{array}$ & $\begin{array}{l}\text { Proteína } \\
\text { bruta } \\
(\% \mathrm{MS})\end{array}$ & $\begin{array}{l}\text { PIDN } \\
\text { (\% PB) }\end{array}$ & $\begin{array}{l}\text { PIDA } \\
(\% \quad \text { PB) }\end{array}$ & $\begin{array}{l}\text { Extrato } \\
\text { etéreo } \\
\text { (\% MS) }\end{array}$ & $\begin{array}{l}\text { FDNcp } \\
\text { (\%MS) }\end{array}$ & $\begin{array}{c}\text { Carboidratos } \\
\text { não-fibrosos } \\
(\% \mathrm{MS})\end{array}$ & $\begin{array}{c}\text { Fibra em } \\
\text { detergenteácido } \\
\text { (\%MS) }\end{array}$ & $\begin{array}{l}\text { Lignina } \\
\text { (\% MS) }\end{array}$ \\
\hline Abacaxi & 13,91 & 95,27 & 7,09 & 50,49 & 44,38 & 0,78 & 60,20 & 27,20 & 34,11 & 3,71 \\
\hline Dendê & 92,44 & 97,04 & 16,10 & 94,91 & 58,32 & 10,71 & 52,30 & 17,93 & 35,94 & 11,18 \\
\hline Farelo de glúten & 85,76 & 94,22 & 21,86 & 38,24 & 13,26 & 2,84 & 22,68 & 46,84 & 12,46 & 1,44 \\
\hline Feijão & 87,22 & 95,54 & 23,92 & 35,83 & 25,44 & 1,95 & 29,48 & 40,19 & 6,69 & 0,18 \\
\hline Mamão & 10,07 & 94,93 & 14,80 & 86,87 & 27,41 & 7,28 & 29,38 & 43,48 & 32,74 & 7,74 \\
\hline Mandioca casca & 25,56 & 96,63 & 3,73 & 58,82 & 7,41 & 0,59 & 15,75 & 76,56 & 15,56 & 5,54 \\
\hline Mandioca haste & 89,98 & 96,26 & 5,44 & 47,15 & 21,34 & 0,92 & 65,11 & 24,79 & 57,12 & 20,01 \\
\hline Mandioca rama & 21,85 & 91,81 & 24,17 & 59,80 & 55,96 & 2,38 & 40,44 & 24,82 & 36,26 & 9,61 \\
\hline Manga & 34,50 & 97,61 & 5,05 & 79,17 & 22,64 & 4,00 & 32,55 & 56,01 & 23,78 & 7,25 \\
\hline Maracujá & 19,53 & 96,32 & 9,97 & 17,98 & 7,70 & 12,20 & 54,77 & 19,38 & 42,70 & 7,79 \\
\hline
\end{tabular}

PIDN = proteína insolúvel em detergente neutro, PIDA = proteína insolúvel em detergente ácido; FDNcp = fibra em detergente neutro livre de cinzas e proteína 
- EEad $=(E E-1)-0,62 \times 100$ para EE $>1 \%$ na MS e para $\mathrm{EE} \leq 1 \%$ na MS então, EEad = 0 (NRC, 2001);

— EEad = 0,8596 $\times \mathrm{EE}-0,18$ (Detmann et al., 2006b);

$-\mathrm{CNFad}=0,98 \times \mathrm{CNF}-3,1$ (NRC, 2001);

- CNFad = 0,9507 $\times$ CNF -5,11 (Detmann et al., 2006c);

$-\mathrm{FDNd}=0,75(\mathrm{FDNcp}-\mathrm{L}) \times\left[1-(\mathrm{L} / \mathrm{FDNcp})^{0,667}\right]$, em que $\mathrm{L}=$ lignina (NRC, 2001);

$-\mathrm{FDNd}=0,835(\mathrm{FDNcp}-\mathrm{L}) \times\left[1-(\mathrm{L} / \mathrm{FDNcp})^{0,85}\right]$, em que $\mathrm{L}$ = lignina (Detmann et al., 2007);

$-\mathrm{ED}(\mathrm{Mcal} / \mathrm{kg})=\mathrm{PBd} / 100 * 5,6+\mathrm{EEd} / 100 * 9,4+\mathrm{CNFd} /$ $100 * 4,2+\mathrm{FDNd} / 100 * 4,2$ (NRC, 2001);

As equações propostas por Detmann et al. (2006a, 2006b, 2006c, 2007, 2008a) serão chamadas apenas de Detmann com a distinção entre as duas propostas para PBd as quais serão mencionadas como 1 (Detmann et al., 2006a) e 2 (Detmann et al., 2008a).

A validação dos parâmetros PBad, EEad, CNFad e FDNvd foi realizada a partir de 14 observações obtidas com novilhas em crescimento alimentadas com dietas contendo dois níveis de subprodutos.

Os procedimentos para validação das frações digestíveis observadas e preditas pelas equações adotadas pelo NRC (2001) e sugeridas por Detmann et al. (2006a, 2006b, 2006c, 2007, 2008a) basearam-se no ajustamento do modelo de regressão linear simples dos valores observados (variável dependente) sobre os valores preditos (variável independente) pelas equações, sendo as estimativas dos parâmetros de regressão testadas pela hipótese de nulidade conjunta segundo Mayer et al. (1994):

Ho : $\beta_{0}=0$ e $\beta_{1}=1$ X Ha : não Ho.

Sob o caso de não rejeição da hipótese de nulidade, conclui-se pela equivalência entre os valores observados e preditos pelas equações.
O viés médio foi calculado conforme Cochran \& Cox (1957), segundo a equação $\mathrm{VM}=\frac{1}{n} \sum_{i=1}^{n}(x i-y i)$, em que: $\mathrm{x}=$ valores observados; $\mathrm{y}=$ valores preditos.

O coeficiente de correlação concordante (CCC), também conhecido como índice de reprodutibilidade, que considera simultaneamente exatidão e precisão, foi calculado conforme Lin (1989).

A avaliação comparativa da eficiência de predição das equações foi realizada pela avaliação do quadrado médio dos erros de predição (QMEP), segundo descrito por Bibby \& Toutenburg (1977), conforme a equação abaixo:

$\mathrm{QMEP}=\frac{1}{n} \sum_{i=1}^{n}(x i-y i)^{2}$; em que: $\mathrm{x}=$ valores observados; y = valores preditos. Faz-se necessário uma ressalva de que para todos os cálculos de variância, empregou-se como divisor o total de observações (n).

Para todos os procedimentos estatísticos, fixou-se em 0,05 o nível crítico de probabilidade para o erro tipo 1 . Todos os procedimentos estatísticos foram realizados utilizando-se o programa Model Evaluation System (MES), versão 3.0.11.

\section{Resultados e Discussão}

Com base na estatística descritiva para o conjunto total de dados utilizado para predição do valor energético dos subprodutos, pode-se verificar ampla variabilidade do valor nutricional entre as dietas contendo os diferentes subprodutos, principalmente se observados o consumo e a digestibilidade das frações nutricionais (Tabela 2).

De acordo com os resultados dos parâmetros das regressões e das avaliações da exatidão dos modelos adotados pelo NRC (2001) e os sugeridos por Detmann et al. (2006a - 1 e 2008a - 2) para PBad, o modelo Detmann 2

Tabela 2 - Estatística descritiva para o conjunto de dados utilizado para predição do valor energético de subprodutos agrícolas e agroindustriais

\begin{tabular}{|c|c|c|c|c|c|c|}
\hline Item & Média & Mediana & Mínimo & Máximo & Desvio-padrão & CV (\%) \\
\hline & \multicolumn{6}{|c|}{ Consumo, kg/dia } \\
\hline Matéria seca & 4,84 & 4,81 & 2,43 & 7,43 & 1,01 & 9,55 \\
\hline Matéria orgânica & 4,58 & 4,57 & 2,27 & 6,98 & 0,98 & 9,23 \\
\hline Proteína bruta & 0,62 & 0,63 & 0,31 & 1,18 & 0,14 & 1,34 \\
\hline Extrato etéreo & 0,27 & 0,26 & 0,10 & 0,56 & 0,08 & 0,91 \\
\hline FDNcp & 2,61 & 2,63 & 1,45 & 3,82 & 0,54 & 5,06 \\
\hline \multirow[t]{2}{*}{ Carboidratos não-fibrosos } & 1,21 & 1,14 & 0,15 & 2,57 & 0,52 & 4,96 \\
\hline & \multicolumn{6}{|c|}{ Digestibilidade, \% } \\
\hline Matéria seca & 59,20 & 60,07 & 34,57 & 76,17 & 6,91 & 68,11 \\
\hline Matéria orgânica & 63,15 & 63,65 & 38,72 & 81,88 & 7,70 & 74,83 \\
\hline Proteína bruta & 69,76 & 69,25 & 48,09 & 92,75 & 9,59 & 95,90 \\
\hline Extrato etéreo & 89,37 & 90,08 & 72,85 & 96,83 & 4,65 & 44,92 \\
\hline FDNcp & 56,67 & 57,83 & 21,24 & 75,33 & 8,41 & 83,32 \\
\hline Carboidratos não-fibrosos & 65,20 & 65,20 & 36,17 & 88,33 & 10,26 & 115,42 \\
\hline
\end{tabular}


diferiu $(\mathrm{P}<0,05)$ pelo teste de hipótese para nulidade conjunta (Mayer et al., 1994) e, assim, os valores preditos por esse modelo não apresentaram equivalência com os valores observados (Tabela 3; Figura 1).

Entre os modelos de predição para PBad, o modelo Detmann 2 diferiu $(\mathrm{P}<0,05)$ pelo teste de hipótese para nulidade conjunta (Mayer et al., 1994) e, assim, os valores preditos por este modelo não apresentaram equivalência com os valores observados. No entanto, se forem considerados os subprodutos de dendê e mandioca rama como out lines, pois apresentaram valores negativos, as estimativas por este modelo seriam a de maior coeficiente de determinação $(0,930)$, as com maior exatidão e precisão simultaneamente (CCC $=0,961)$, além de ser a com menor QMEP $(6,289)$.

A explicação para o fato de os subprodutos de dendê e mandioca rama apresentarem estimativas negativas para PBad pelo modelo proposto por Detmann 2 parece ser as estimativas de PIIDN. Como os valores desta fração não foram determinados biologicamente, as estimativas pelo modelo proposto por Detmann et al. (2010) superestimaram a PIIDN para os subprodutos de dendê e mandioca rama.
O maior entrave da predição da PBad pode estar relacionado com a estimativa da fração do nitrogênio indisponível no trato gastrintestinal. Para Sniffen et al. (1992), a PIDA seria o melhor estimador do potencial protéico dos alimentos disponíveis para os microrganismos ruminais, sendo considerado indisponível durante sua permanência no trato gastrintestinal dos ruminantes. No entanto, Detmann et al. (2004) e Detmann et al. (2003) demonstraram ausência de relação entre a fração dos compostos nitrogenados não degradável no rúmen e PIDA e a possibilidade de parte da PIDA ser digestível no intestino.

Portanto, Detmann et al. (2008a) sugeriram que os maiores ganhos de precisão e exatidão das estimativas de PBad poderiam ser observados pela obtenção de teores de PIIDN por meio de ensaios biológicos. Proposto por Detmann et al. (2004), estes ensaios biológicos, permitem considerar a fração não degradável como um conceito biológico, a qual sofre influências diretas e interações entre efeitos químicos, fisiológicos, anatômicos e ambientais, limitando potencialmente o acesso microbiano.

Tabela 3 - Estatística para regressão entre os valores observados e preditos pelos modelos sugeridos pelo NRC e Detmann 1 e 2 para proteína bruta aparente digestível

\begin{tabular}{lrrr}
\hline Item & \multicolumn{3}{c}{ Proteína bruta aparente digestível } \\
\cline { 2 - 4 } & NRC & Detmann 1 & Detmann 2 \\
\hline Intercepto & 0,036 & $-1,308$ & 10,558 \\
Inclinação & 0,916 & 1,115 & $-0,057$ \\
$\mathrm{r}^{2}$ & 0,819 & 0,875 & 0,041 \\
Valor P (Ho: a = 0 e b = 1) & 0,569 & $-0,647$ & 0,001 \\
Viés médio, \% & $-0,936$ & 0,921 & 11,640 \\
Coeficiente de correlação concordante & 0,900 & 10,843 & $-0,094$ \\
Quadrado médio do erro de predição, \% & 15,988 & & $1.347,524$ \\
\hline
\end{tabular}
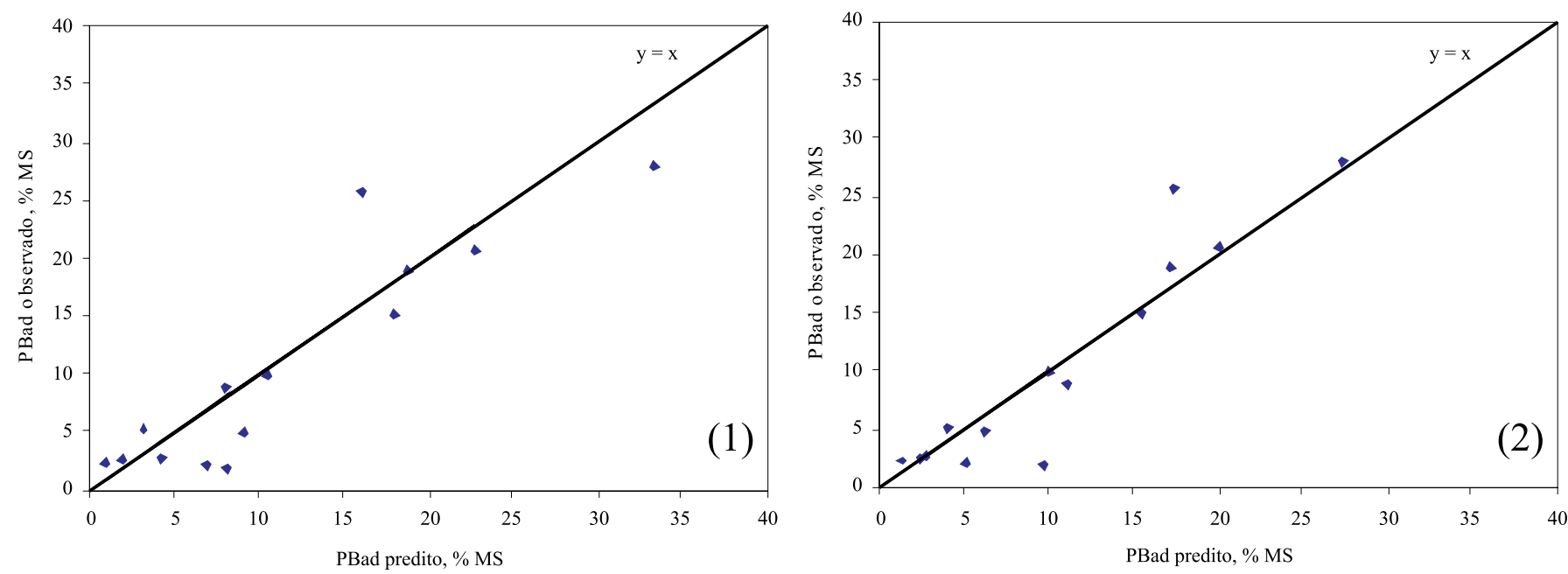

Figura 1 - Relação entre os valores de proteína bruta aparente digestível (PBad) observados e preditos pela equação do NRC (2001) (1) e Detmann et al. (2006a) (2). 
Visualmente, as diferenças entre os modelos propostos pelo NRC (2001) e Detmann 1 para estimativas da PBad são pouco perceptíveis (Figura 1). Observa-se que houve pouca dispersão dos valores em torno da reta de equalidade ( $\mathrm{Y}=\mathrm{X}$, com $\mathrm{r}^{2}=0,819$ e 0,875$)$ para NRC (2001) e Detmann 1, respectivamente, para os dois modelos e uma grande amplitude de valores dentro do espectro de predição, variando in vivo entre 1,9 a 27,9\% de PBad para os subprodutos de goiaba e girassol, respectivamente.

As estimativas dos teores de PBad pelos modelos NRC e Detmann 1 foram similares às obtidas pelas observações in vivo ( $\mathrm{P}>0,05)$, se for considerada a hipótese de nulidade conjunta (Mayer et al., 1994). Resultado semelhante também foi observado por Magalhães (2007) com forragens tropicais. Na avaliação comparativa da eficiência de predição, os valores estimados pelo modelo de Detmann 1 apresentaram estimativas mais precisas, além de ser o modelo com valor do VM $(-0,076)$ mais próximo de zero.

Por apresentar o VM negativo pode-se afirmar que os dois modelos apresentam uma tendência a superestimar os valores observados das frações de PBad em subprodutos e observou-se que o maior erro de predição entre todos os valores preditos foi de $-9,618$ e -8,329\% da PBad na MS para os modelos NRC (2001) e Detmann 1, respectivamente, para o subproduto mandioca rama. Pina et al. (2006) também observaram predições superestimadas do NRC (2001) para alimentos em condições tropicais.

Apesar do aparente ajustamento dos valores observados com os valores preditos para EEad (Figura 2) em relação à reta de equalidade ( $\mathrm{Y}=\mathrm{X}$, com $\mathrm{r}^{2}=0,978$ ) no modelo adotado pelo NRC (2001), esse diferiu $(\mathrm{P}<0,05)$, pelo teste de significância da hipótese de nulidade conjuntas (Tabela 4). Isso indica ausência de equivalência entre os valores preditos pelo modelo adotado pelo NRC (2001) e os valores observados de EEad, resultado semelhante ao observado por Magalhães (2007) para forragens tropicais.

Houve melhor ajustamento para o modelo sugerido por Detmann e, como consequência, não diferiu $(\mathrm{P}>0,05)$ pelo teste de significância da hipótese de nulidade conjunta, permitindo afirmar que existiu equivalência entre os valores preditos e os observados de EEad (Tabela 4).

A precisão e exatidão do modelo sugerido por Detmann para EEad podem ser observadas principalmente pelo baixo QMEP $(0,587)$, VM $(-0,128)$ e CCC $(0,989)$. Além disso, existem pontos no eixo Y (Figura 2) indicando que em alimentos com EE menor que 1\% na MS, como os

Tabela 4 - Estatística para regressão entre os valores observados e preditos pelos modelos sugeridos pelo NRC e Detmann para extrato etéreo aparente digestível

\begin{tabular}{lcc}
\hline Item & \multicolumn{2}{c}{ Extrato etéreo aparente digestível } \\
\cline { 2 - 3 } & NRC & Detmann \\
\hline Intercepto & 0,984 & 0,053 \\
Inclinação & 0,847 & 0,963 \\
$\mathrm{r}^{2}$ & 0,979 & 0,980 \\
Valor P (Ho: a = 0 e b = 1) & 0,003 & 0,553 \\
Viés médio, \% & 0,298 & $-0,128$ \\
Coeficiente de correlação concordante & 0,976 & 0,989 \\
Quadrado médio do erro de predição, \% & 1,528 & 0,587 \\
\hline
\end{tabular}
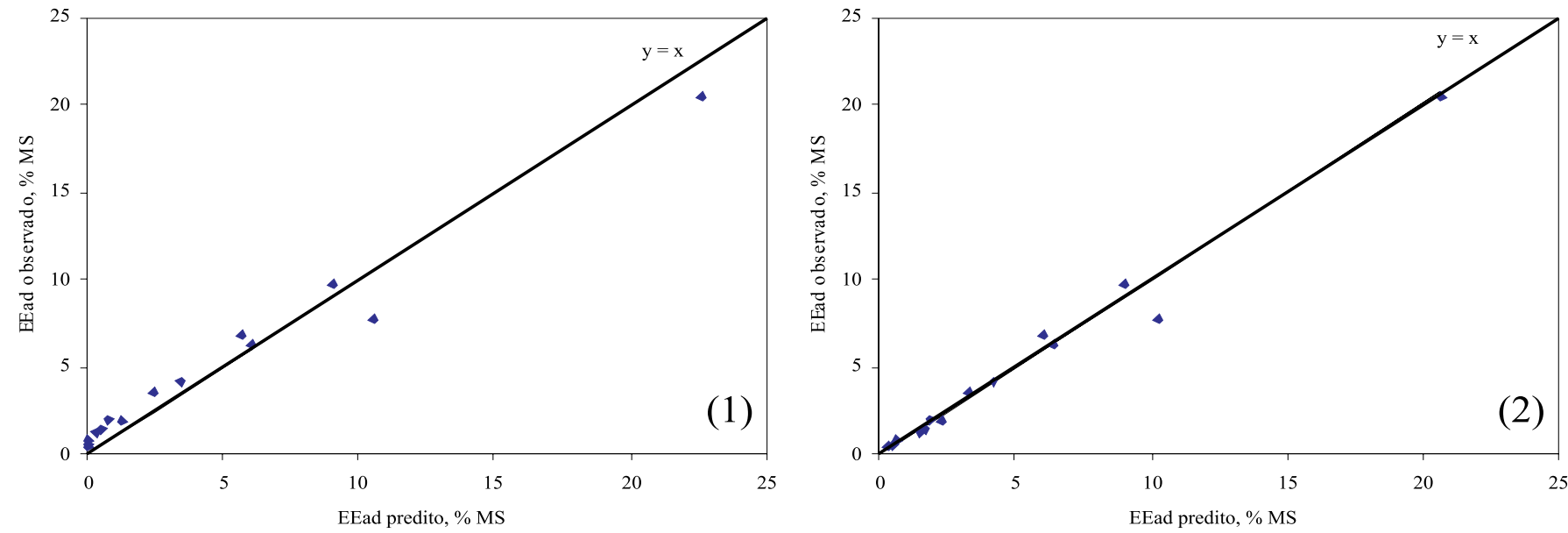

Figura 2 - Relação entre os valores do extrato etéreo aparente digestível (EEad) observados e preditos pela equação do NRC (2001) (1) e Detmann (2). 
observados para os subprodutos de abacaxi, mandioca casca e mandioca haste, o modelo NRC (2001) considera como zero as estimativas de EEad, o que não é real. Silva et al. (2007) também observaram valor zero predito pelo NRC (2001) para EEad em capim elefante com idade de rebrota de 48, 63 e 78 dias.

Dessa forma, as estimativas de EEad adotadas pelo modelo do NRC (2001), ao considerar a correção por uma constante induziu a um maior VM $(0,298)$, menor precisão e exatidão (CCC $=0,976)$ e possibilitou maior QMEP $(1,528)$, quando comparado ao modelo proposto por Detmann, o qual utiliza um fator multiplicativo constante (considerado como coeficiente de digestibilidade verdadeira) associado à contribuição metabólica fecal. Pina et al. (2006) e Silva et al. (2007) observaram que o modelo do NRC (2001) tende a subestimar a predição do EEad para alimentos em condições tropicais.

Não houve equivalência $(\mathrm{P}<0,05)$ para a fração de CNFad entre os valores preditos pelo modelo adotado pelo NRC (2001) e os valores observados em condições práticas de alimentação com subprodutos por bovinos em condições tropicais (Tabela 5; Figura 3).

O modelo sugerido por Detmann foi mais adequado, uma vez que não houve rejeição da hipótese de nulidade avaliada (P>0,05). Magalhães (2007) também observou maior precisão para o modelo sugerido por Detmann et al. (2006c). Esse modelo apresenta tendência de superestimar os valores da fração de CNFad de subprodutos e isto pode ser observado pelo sinal negativo do $\operatorname{VM}(-2,159)$.

Ao comparar o valor do erro de predição para o maior valor, observou-se estimativa de 16,266 pontos percentuais a mais para CNFad da mandioca casca, que teve in vivo CNFad de 51,41\% na MS (Tabela 5).

Segundo Detmann et al. (2006c), estas diferenças são decorrentes de variações no consumo total de CNF inerentes a cada animal, o que resulta em variações na porção metabólica fecal.

A adoção do modelo proposto por Detmann para a fração de CNFad, apresentou maior precisão e exatidão (CCC = 0,920) e também, resultou em QMEP 38,16\% menor

Tabela 5 - Estatística para regressão entre os valores observados e preditos pelos modelos sugeridos pelo NRC (2001) e Detmann et al. (2006c) para carboidratos não-fibrosos aparentemente digestíveis

\begin{tabular}{lcc}
\hline Item & Carboidratos não-fibrosos aparentemente digestíveis \\
\cline { 2 - 3 } & NRC & Detmann \\
\hline Intercepto & $-0,223$ & 1,592 \\
Inclinação & 0,838 & 0,863 \\
r $^{2}$ & 0,867 & 0,867 \\
Valor P (Ho: a = 0 e b = 1) & 0,011 & 0,191 \\
Viés médio, \% & $-5,173$ & $-2,159$ \\
Coeficiente de correlação concordante & 0,883 & 0,920 \\
Quadrado médio do erro de predição, \% ${ }^{2}$ & 64,404 & 39,826 \\
\hline
\end{tabular}
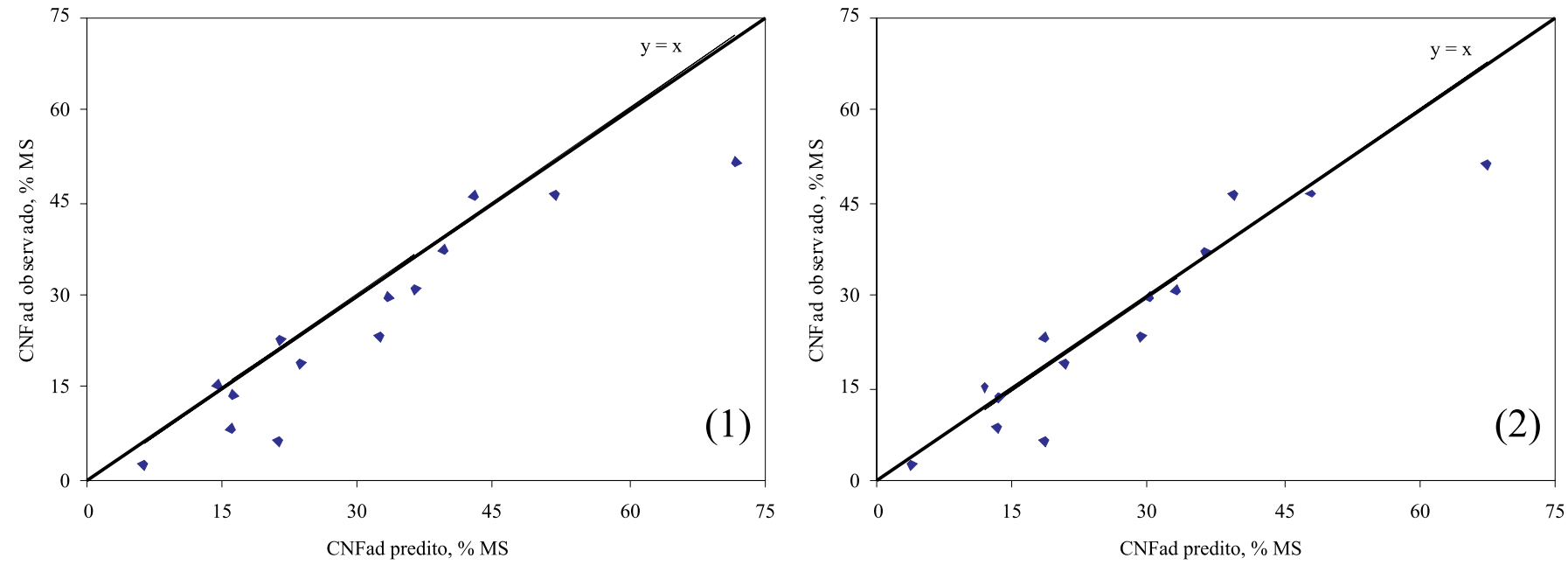

Figura 3 - Relação entre os valores dos carboidratos não-fibrosos aparentemente digestíveis (CNFad) observados e preditos pela equação do NRC (2001) (1) e Detmann (2). 
do que os valores estimados com modelo adotado pelo NRC (2001). Pina et al. (2006) verificaram que o modelo adotado pelo NRC (2001) subestima os CNFd.

Os modelos do NRC e Detmann foram considerados ineficiente e eficiente, respectivamente, em predizer os teores de FDNd, pelo teste da hipótese de nulidade conjunta, segundo Mayer et al. (1994) (Tabela 6; Figura 4).

Entre todas as frações digestíveis, a fração digestível da FDN (FDNd) foi a que apresentou maior dispersão dos pontos em relação a linha de equalidade $(\mathrm{Y}=\mathrm{X})$. Notou-se também, que o modelo sugerido por Detmann não foi tão exato e preciso para estimar os valores da FDNd, como aqueles sugeridos por Detmann para estimar as frações de PBad, EEad e CNFad, já que os valores de CCC foram superiores a 0,723. Essa falta de ajuste no modelo refletiu diretamente no coeficiente de determinação $\left(\mathrm{r}^{2}\right)$, o qual foi inferior a 0,59 e no alto QMEP que foi superior a $78 \%{ }^{2}$. O modelo adotado pelo NRC (2001) apresentou VM $(6,951)$, indicando subestimação da FDNd, com comportamento semelhante ao observado por Detmann et al. (2004) e Pina et al. (2006).
Nesse sentido, a aplicabilidade desses modelos torna-se limitada, em virtude da elevada concentração de componentes fibrosos em subprodutos tropicais, tornando necessário o desenvolvimento de novos modelos que sejam precisos e exatos para estimar o valor energético de subprodutos agrícolas e agroindustriais.

Rocha Júnior et al. (2003), Detmann et al. (2004), Costa et al. (2005), Pina et al. (2006), Oliveira et al. (2007) e Silva et al. (2007) observaram que os modelos de predição das frações digestíveis propostas pelo NRC (2001) não foram adequados para predizer as frações digestíveis dos alimentos em condições brasileiras.

Erros de predições superiores a 15\% foram observados nas estimativas do modelo NRC para o NDT de subprodutos (Tabela 7): dendê (-16,59\%), goiaba (14,07\%), mandioca rama $(-34,97)$ e maracujá $(17,86 \%)$. Enquanto para as estimativas de NDT do modelo de Detmann et al. (2008b), os erros de predição superiores a 15\% foram observados com os subprodutos de goiaba $(17,01 \%)$, mandioca rama (-30,03\%) e maracujá $(17,90 \%)$.

Tabela 6 - Estatística para regressão entre os valores observados e preditos pelos modelos sugeridos pelo NRC (2001) e Detmann et al. (2007) para fibra em detergente neutro digestível

\begin{tabular}{lcc}
\hline Item & Fibra em detergente neutro digestível \\
\cline { 2 - 3 } & NRC & Detmann \\
\hline Intercepto & 5,816 & 4,863 \\
Inclinação & 1,075 & 0,915 \\
r $^{2}$ & 0,560 & 0,581 \\
Valor P (Ho: a = 0 e b = 1) & 0,042 & 0,388 \\
Viés médio, \% & 6,951 & 3,265 \\
Coeficiente de correlação concordante & 0,590 & 0,723 \\
Quadrado médio do erro de predição, \% & 119,095 & 78,505 \\
\hline
\end{tabular}
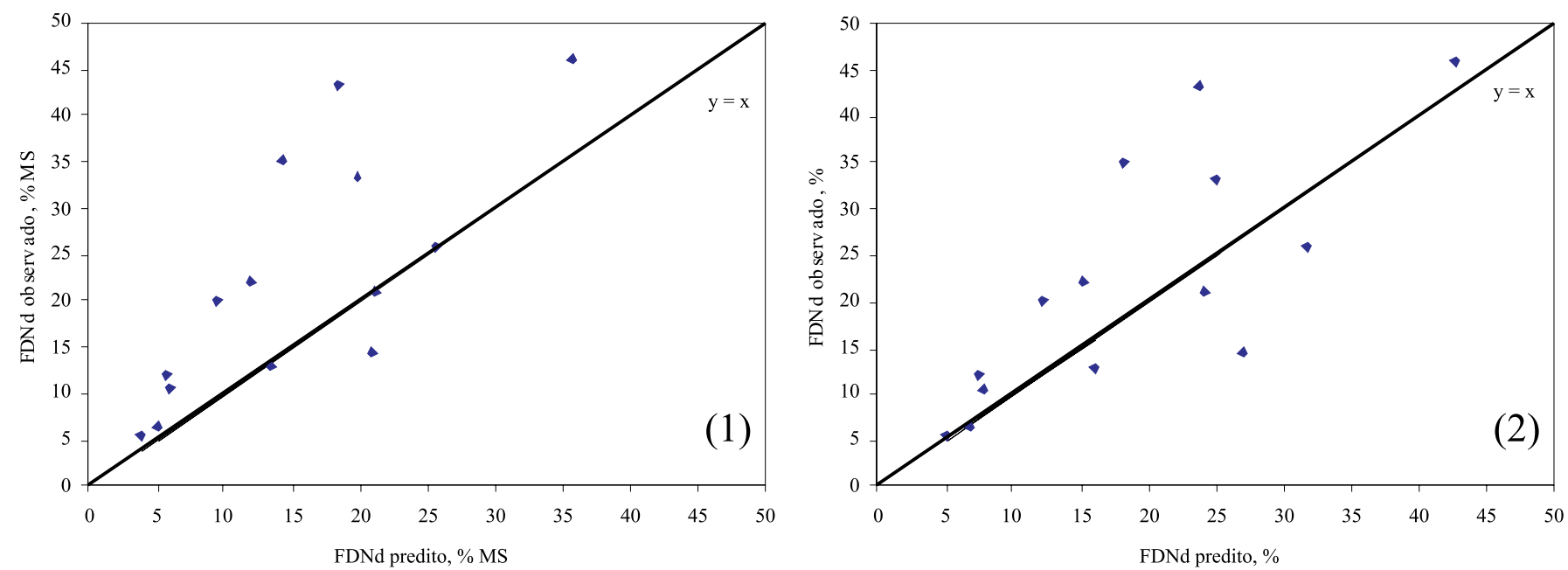

Figura 4 - Relação entre os valores da fibra em detergente neutro digestível (FDNd) observados e preditos pela equação do NRC (2001) (1) e Detmann (2) 
Nas estimativas de energia digestível para o modelo NRC (2001) os maiores erros foram observados para os subprodutos de goiaba $(0,85 \mathrm{Mcal} / \mathrm{kg})$, mandioca haste (1,36 Mcal/kg), mandioca rama (-1,14 Mcal/kg) e maracujá (0,81 Mcal $/ \mathrm{kg}$ ). Já para o modelo de Detmann et al. (2008b) as maiores distorções foram observadas para os subprodutos goiaba, mandioca haste e mandioca rama, onde os erros de predição foram de 0,$95 ; 1,44$ e-0,91 Mcal $/ \mathrm{kg}$, respectivamente.

De acordo com a estatística para regressão entre os valores observados e preditos pelos modelos sugeridos pelo NRC e Detmann para NDT e ED, houve aceitação da hipótese de nulidade $(\mathrm{P}>0,05)$, significando que esses modelos estariam aptos a predizer o valor energético (NDT e ED) de subprodutos agrícolas e agroindustriais em condições brasileiras (Tabela 8; Figuras 5 e 6).

Costa et al. (2005) e Pereira et al. (2008) também observaram que os modelos do NRC (2001) foram eficientes para determinação do valor energético (NDT) dos alimentos estudados nas condições brasileiras. No entanto, para o NDT, houve grande dispersão dos pontos em relação à linha de equalidade $(\mathrm{Y}=\mathrm{X})$. Essa variabilidade dos pontos (Figura 5) pode ser mais bem interpretada se observados, nos modelos avaliados, o elevado valor do QMEP (superior a $164 \%{ }^{2}$ ), os baixos valores do ${ }^{2}$ (inferior a $41 \%$ ), CCC (inferior a 0,59) e principalmente que, apesar de os modelos serem exatos, não foram precisos em estimar os valores energéticos observados para os subprodutos agrícolas e agroindustriais.

Numa análise mais criteriosa, pode-se dizer que os resultados da regressão para o valor energético dos subprodutos estimados pelo modelo do NRC (2001) foram incoerentes biologicamente, já que apenas para o modelo da PBad existiu equivalência $(\mathrm{P}>0,05)$ entre os valores observados. Isso porque, o valor energético de um alimento ou dieta é obtido da energia de cada uma das frações nutricionais e essas são independentes. Dessa forma, o valor energético do alimento poderia ser expresso como a soma algébrica simples das partes, ou seja, por um processo somativo, no qual não seriam consideradas interações entre as partes, pois, caso isso ocorresse, migrar-se-ia de um sistema somativo para um sistema interativo (Detmann et al. 2008c).

Tabela 7 - Valores de nutrientes digestíveis totais (NDT) e energia digestível (ED) observados in vivo e preditos pelos modelos propostos pelo NRC e Detmann

\begin{tabular}{|c|c|c|c|c|c|c|}
\hline \multirow[t]{3}{*}{ Item } & \multicolumn{3}{|c|}{ NDT, \% } & \multicolumn{3}{|c|}{ ED, Mcal/kg } \\
\hline & \multirow{2}{*}{$\frac{\text { Observado }}{\text { in vivo }}$} & \multicolumn{2}{|c|}{ Predito } & \multirow{2}{*}{$\frac{\text { Observado }}{\text { in vivo }}$} & \multicolumn{2}{|c|}{ Predito } \\
\hline & & NRC & Detmann & & NRC & Detmann \\
\hline Abacaxi & 71,75 & 60,56 & 68,56 & 3,14 & 2,67 & 2,93 \\
\hline Cacau casquinha & 41,23 & 53,37 & 55,19 & 1,74 & 2,35 & 2,45 \\
\hline Dendê & 79,33 & 62,74 & 68,35 & 3,47 & 2,74 & 3,02 \\
\hline Farelo de glúten de milho & 78,28 & 76,95 & 76,08 & 3,57 & 3,48 & 3,41 \\
\hline Feijão bandinha & 73,68 & 77,06 & 77,76 & 3,36 & 3,50 & 3,51 \\
\hline Girassol & 73,07 & 73,62 & 68,69 & 3,46 & 3,56 & 3,27 \\
\hline Goiaba & 33,45 & 47,52 & 50,46 & 1,24 & 2,09 & 2,19 \\
\hline Mamão & 82,40 & 72,28 & 72,16 & 3,63 & 3,18 & 3,17 \\
\hline Mandioca casca & 60,30 & 74,37 & 74,75 & 2,56 & 3,23 & 3,16 \\
\hline Mandioca haste & 54,37 & 42,26 & 46,33 & 0,54 & 1,90 & 1,98 \\
\hline Mandioca rama & 88,22 & 53,25 & 58,19 & 3,60 & 2,46 & 2,69 \\
\hline Manga & 79,02 & 71,05 & 73,05 & 3,44 & 3,01 & 3,10 \\
\hline Maracujá & 56,57 & 74,43 & 74,47 & 2,44 & 3,25 & 3,21 \\
\hline Nabo & 90,76 & 95,94 & 87,92 & 4,08 & 4,34 & 3,96 \\
\hline
\end{tabular}

Tabela 8 - Estatística para regressão entre os valores observados e preditos pelos modelos sugeridos pelo NRC e Detmann para nutrientes digestíveis totais (NDT) e energia digestível (ED)

\begin{tabular}{|c|c|c|c|c|}
\hline \multirow[t]{2}{*}{ Item } & \multicolumn{2}{|c|}{ Nutrientes digestíveis totais } & \multicolumn{2}{|c|}{ Energia digestível } \\
\hline & NRC & Detmann & NRC & Detmann \\
\hline Intercepto & 22,109 & 4,255 & $-0,623$ & $-2,074$ \\
\hline Inclinação & 0,698 & 0,948 & 1,173 & 1,648 \\
\hline$r^{2}$ & 0,338 & 0,404 & 0,554 & 0,702 \\
\hline Valor P (Ho: $\mathrm{a}=0 \mathrm{e} \mathrm{b}=1)$ & 0,518 & 0,968 & 0,735 & 0,123 \\
\hline Viés médio, \% & 1,931 & 0,748 & $-0,107$ & $-0,127$ \\
\hline Coeficiente de correlação concordante & 0,567 & 0,587 & 0,668 & 0,669 \\
\hline Quadrado médio do erro de predição, \% & 202,753 & 164,275 & 0,471 & 0,424 \\
\hline
\end{tabular}



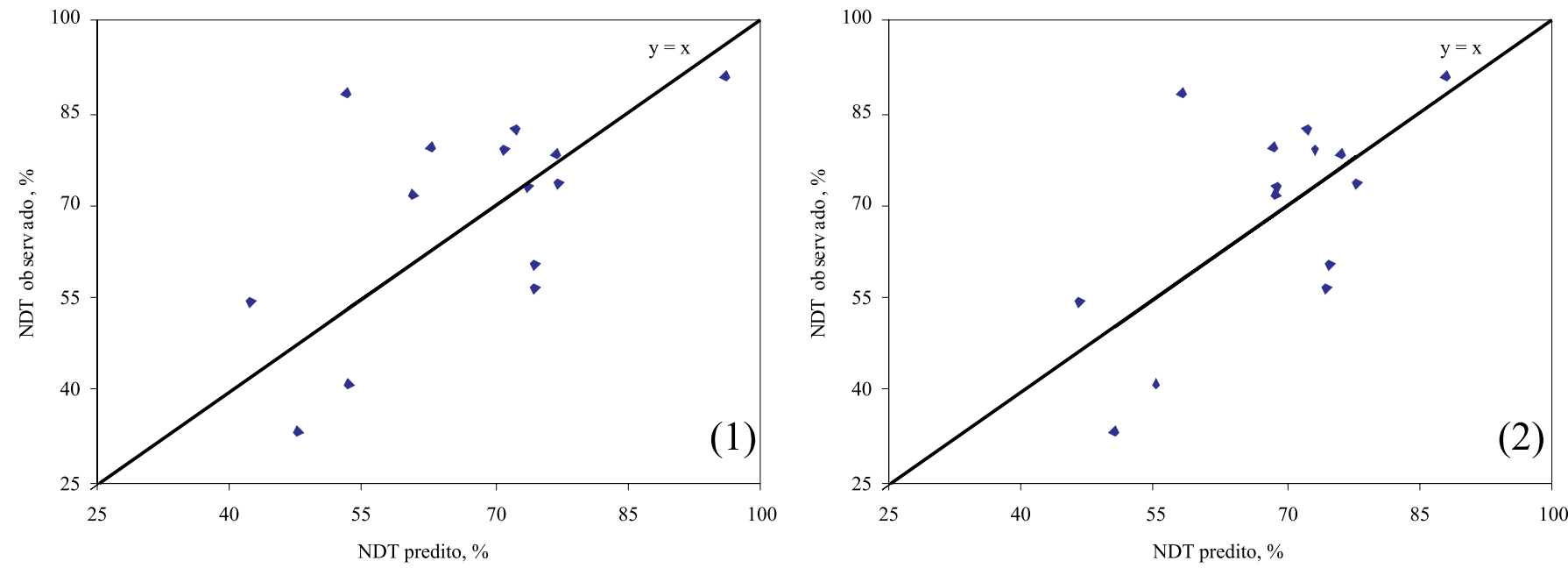

Figura 5 - Relação entre os valores de nutrientes digestíveis totais (NDT) observados e preditos pela equação do NRC (2001) (1) e Detmann (2).
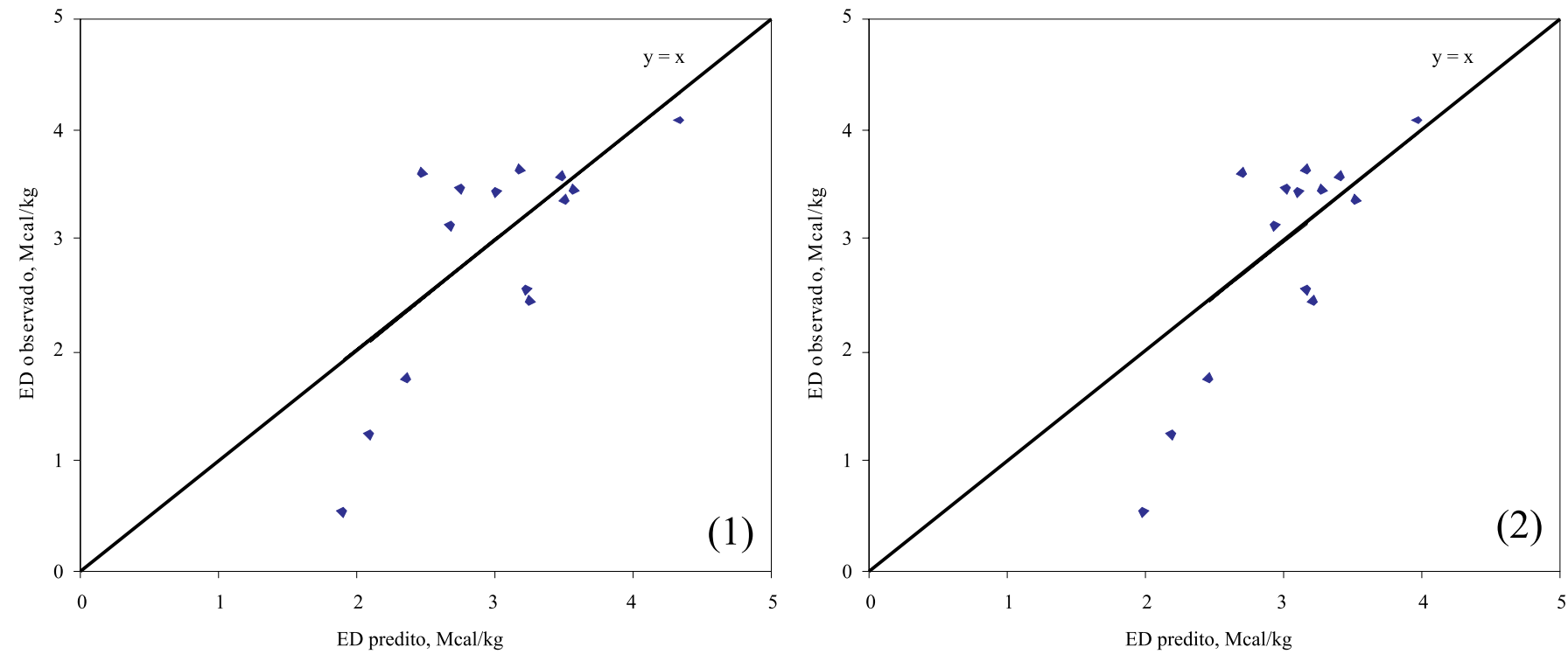

Figura 6 - Relação entre os valores de energia digestível (ED) observados e preditos pela equação do NRC (2001) (1) e Detmann (2).

Como os dois modelos foram baseados em sistemas somativos, a precisão e exatidão da predição das frações digestivas de PB, EE e CNF para o modelo de Detmann foram anulados pela falta de precisão da fração de FDNd em predizer com maior precisão o valor energético dos subprodutos (Tabela 9). Enquanto, para o modelo NRC, as divergências de cada fração digestível quantificadas separadamente, possibilitaram que estimativas de valor energético (NDT) pudessem se tornar válidas estatisticamente.
Tabela 9 - Viés médio para as frações digestíveis obtidas pelo NRC (2001) e Detmann

\begin{tabular}{lcc}
\hline Item & \multicolumn{2}{c}{ Viés médio } \\
\cline { 2 - 3 } & NRC & Detmann \\
\hline PBad & $-0,936$ & $-0,076$ \\
EEad & 0,298 & $-0,128$ \\
CNFad & $-5,173$ & $-2,159$ \\
FDNd & 6,951 & 3,265 \\
Soma total & 1,14 & 0,902 \\
\hline
\end{tabular}

PBad = proteína bruta aparentemente digestível; EEad = extrato etéreo aparentemente digestível; CNFad = carboidratos não-fibrosos aparentemente digestíveis; FDNd = fibra em detergente neutro digestível. 
Neste contexto, existe falsa impressão que é possível utilizar o modelo NRC (2001) para estimar o valor energético de subprodutos agrícolas e agroindustriais em condições tropicais, pois, não é possível o balanceamento de rações para bovinos desconsiderando as partes (PBad, EEad, CNFad e FDNd) que são capazes de produzir energia no sistema biológico representado pelo animal ruminante.

Considerando que o modelo de Detmann apresentou maior $\mathrm{r}^{2}$, menor QMEP, menor viés médio e maior CCC em todas as frações digestíveis em relação ao modelo NRC (2001), além de ter sido desenvolvido exclusivamente com base em informações de alimentos produzidos nos trópicos, sugere-se que esse modelo seja mais adequado para estimar a energia de subprodutos do que o NRC (2001).

\section{Conclusões}

Recomenda-se usar os modelos propostos por Detmann para predizer as frações digestíveis da proteína bruta, extrato etéreo e carboidratos não-fibrosos em subprodutos agrícolas e agroindustriais. Há necessidade de mais pesquisas para o desenvolvimento de modelos mais adequados para estimar a fração digestível da fibra em detergente neutro, já que esta foi a principal limitante para estimativas precisas e acuradas do valor energético de subprodutos agrícolas e agroindustriais.

\section{Agradecimentos}

Ao suporte financeiro do CNPq/ CT-AGRO/MCT, da FAPEMIG e da FAPESB.

\section{Referências}

ASSOCIATION OF OFFICIAL ANALYTICAL CHEMISTRY AOAC. Official methods of analysis. 15.ed. Arlington: AOAC International, 1990. 1117p.

BIBby, J.; TOUtenburg, H. Prediction and improved estimation in linear models. New York: John Wiley \& Sons, 1977. 188p.

COCHRAN, W.G.; COX, G.M. Experimental design. New York: John Wiley \& Sons, 1957. 611p.

CONRAD, H.R.; WEISS, W.P.; ODWONGO, W.O. et al. Estimating net energy lactation from components of cell solubles and cell walls. Journal of Dairy Science, v.67, n.2, p.427-436, 1984.

COSTA, M.A.L.; VALADARES FILHO, S.C.; VALADARES, R.F.D. et al. Validação das equações do NRC (2001) para predição do valor energético de alimentos nas condições brasileiras. Revista Brasileira de Zootecnia, v.34, n.1, p.280-287, 2005.

DETMANN, E.; PAULINO, M.F.; ZERVOUDAKIS, J.T. et al. Evaluation of digestibility of acid detergent insoluble nitrogen in cattle grazing a signal grass pasture. In: WORLD CONFERENCE OF ANIMAL PRODUCTION, 9., 2003, Porto Alegre. Proceedings... Porto Alegre: World Association for Animal Production, 2003. (CD-ROM).
DETMANN, E.; ZERVOUDAKIS, J.T.; CABRAL, L.S. et al. Validação de equações preditivas da fração indigestível da fibra em detergente neutro em gramíneas tropicais. Revista Brasileira de Zootecnia, v.33, n.6, p.1866-1875, 2004.

DETMANN, E.; PINA, D.S.; VALADARES FILHO, S.C. et al. Estimação da fração digestível da proteína bruta em dietas para bovinos em condições brasileiras. Revista Brasileira de Zootecnia, v.35, n.5, p.2101-2109, 2006a.

DETMANN, E.; VALADARES FILHO, S.C.; PINA, D.S. et al. Estimação da digestibilidade do extrato etéreo em ruminantes a partir dos teores dietéticos: desenvolvimento de um modelo para condições brasileiras. Revista Brasileira de Zootecnia, v.35, n.4, p.1469-1478, 2006b.

DETMANN, E.; VALADARES FILHO, S.C.; HENRIQUES, L.T. et al. Estimação da digestibilidade dos carboidratos não-fibrosos em bovinos utilizando-se o conceito de entidade nutricional em condições brasileiras. Revista Brasileira de Zootecnia, v.35, n.4, p.1479-1486, 2006c.

DETMANN, E.; VALADARES FILHO, S.C.; HENRIQUES, L.T. et al. Reparametrização do modelo baseado na lei de superfície para predição da fração digestível da fibra em detergente neutro em condições brasileiras. Revista Brasileira de Zootecnia, v.36, n.1, p.155-164, 2007.

DETMANN, E.; MAGALHÃES, K.A.; VALADARES FILHO, S.C. et al. Desenvolvimento de um sub-modelo bi-compartimental para estimação da fração digestível da proteína bruta em bovinos a partir da composição química dos alimentos. Revista Brasileira de Zootecnia, v.37, n.12, p.2215-2221, 2008a.

DETMANN, E.; VALADARES FILHO, S.C.; PINA, D.S. et al. Prediction of the energy value of cattle diets based on the chemical composition of the feeds under tropical conditions. Animal Feed Science and Technology, v.143, p.127-147, 2008b.

DETMANN, E.; PAULinO, M.F.; VALADARES FILHO, S.C. Avaliação nutricional de alimentos ou de dietas? Uma abordagem conceitual. In: SIMPÓSIO DE PRODUÇÃO DE GADO DE CORTE, 6., 2008, Viçosa, MG. Anais... Viçosa, MG: UFV, DZO, 2008c. p.21-51.

DETMANN, E.; SILVA, J.F.C.; CLIPES, R.C. et al. Estimação por aproximação química dos teores de proteína indegradável insolúvel em detergente neutro em forragens tropicais. Arquivo Brasileiro de Medicina Veterinária e Zootecnia, v.62, n.3, p.742-746, 2010.

HALL, M.B. Neutral detergent-soluble carbohydrates. Nutritional relevance and analysis. Gainesville: University of Florida, 2000. 76p.

LICITRA, G.; HERNANDEZ, T.M.; VAN SOEST, P.J. Standardization of procedures for nitrogen fractionation of ruminant feeds. Animal Feed Science and Technology, v.57, p.347-358, 1996.

LIN, L. A concordance correlation coefficient to evaluete reprodutibility. Biometrics, v.45, p.255-268, 1989.

MAGALHÃES, K.A. Tabelas brasileiras de composição de alimentos, determinação e estimativa do valor energético de alimentos para bovinos. 2007. 263f. Tese (Doutorado em Zootecnia) - Universidade Federal de Viçosa, Viçosa, MG.

MAYER, D.G.; STUART, M.A.; SWAIN, A.J. Regression of realworld data on model output: An appropriate overall test of validity. Agriculture System, v.45, p.93-104, 1994.

MERTENS, D.R. Analysis of fiber in feeds and its use in feed evaluation and ration formulation. In: Simpósio Internacional de Ruminantes, 1992, Lavras. Anais... Lavras: Sociedade Brasileira de Zootecnia, 1992. p.1-32.

NATIONAL RESEARCH COUNCIL - NRC. Nutrient requirements of dairy cattle. 7.ed. Washington, D.C.: 2001. 381p.

OLIVEIRA, A.S.; CAMPOS, J.M.S.; VALADARES FILHO, S.C. et al. Substituição do milho por casca de café ou de soja em dietas para vacas leiteiras: consumo, digestibilidade dos 
nutrientes, produção e composição do leite. Revista Brasileira de Zootecnia, v.36, p.1172-1182, 2007.

PEREIRA, E.S.; REGADAS FILHO, J.G.; ARRUDA, A.M.V. et al. Equações do NRC (2001) para predição do valor energético de co-produtos da agroindústria no nordeste brasileiro. Revista Brasileira de Saúde e Produção Animal, v.9, p.258-269, 2008.

PINA, D.S.; VALADARES FILHO, S.C.; DETMANN, E. et al. Efeitos de indicadores e dias de coleta na digestibilidade dos nutrientes e nas estimativas do valor energético de alimentos para vacas alimentadas com diferentes fontes de proteína. Revista Brasileira de Zootecnia, v.35, p.2461-2468, 2006.

ROCHA JÚNIOR, V.R.; VALADARES FILHO, S.C.; BORGES, A.M. et al. Estimativa do valor energético dos alimentos e validação das equações propostas pelo NRC (2001). Revista Brasileira de Zootecnia, v.32, n.2, p.480-490, 2003.

SILVA, J.F.C.; LEÃO, M.I. Fundamentos da nutrição de ruminantes. Piracicaba, Livroceres, 1979. 380p.
SILVA, P.A.; VALADARES FILHO, S.C.; VALADARES, R.F.D. et al. Valor energético do capim-elefante em diferentes idades de rebrota e estimativa da digestibilidade in vivo da fibra em detergente neutro. Arquivo Brasileiro de Medicina Veterinária e Zootecnia, v.59, n.3, p.711-718, 2007.

SNIFFEN, C.J.; O'CONNOR, J.D.; VAN SOEST, P.J. et al. A net carbohydrate and protein system for evaluating cattle diets. II. Carbohydrate and protein availability. Journal of Animal Science, v.70, n.7, p.3562-3577, 1992

VALADARES FILHO, S.C.; BRODERICK, G.A.; VALADARES, R.F.D. et al. Effect of replacing alfalfa silage with high moisture corn on nutrient utilization and milk production. Journal of Dairy Science, v.83, p.106-114, 2000.

VAN SOEST, P.J.; ROBERTSON, J.B. Analysis of forages and fibrous foods. Ithaca: Cornell University, 1985. 202p.

WEISS, W.P.; CONRAD, H.R.; St.PIERRE, N.R. A theoreticallybased model for predicting total digestible nutrient values of forage and concentrates. Animal Feed Science and Technology, v.39, p.95-110, 1992. 